\title{
Fish farming and influenza pandemics
}

\author{
Christoph Scholtissek and Ernest Naylor
}
Human influenza pandemics commonly arise by genetic reassortment between human and avian viruses in pigs. Yet global developments in aquaculture - the so-called 'Blue Revolution' - will mean increased co- location of people, ducks and pigs.

Every 10 to 20 years pandemic influenza A viruses with new surface antigens suddenly appear in nature, against which no neutralizing antibodies are present in the human population. This antigenic shift is caused by genetic reassortment; for example, in the pandemic Hong Kong virus of 1968 the haemagglutinin gene seems to have been contributed to by an avian influenza virus ${ }^{1}$ which normally exists in a quite distinct reservoir of influenza $A$ viruses in water fowl ${ }^{2.3}$.

From experimental studies it seems that although human influenza viruses can multiply in ducks, they are not transmitted among these animals ${ }^{3}$. Presumably, too, avian influenza viruses are not transmitted among human beings, though (for obvious reasons) the experimental basis for that assumption has not been established. In fact the transmission of genetic material from avian to human influenza viruses appears to take place by reassortment in pigs $^{3}$. There is firm evidence that pigs can become infected by and may transmit both human and avian influenza viruses not only amongst other pigs but also back to the original hosts ${ }^{4}$. Therefore, pigs seem to be 'mixing vessels' where the two separate reservoirs meet and where reassortment between avian and human influenza A viruses occurs, giving rise to the antigenic shift by creating new human pandemic influenza strains with new surface antigens.

\section{Agricultural practices}

Age-old agricultural practices in the region of South China, where pigs live in close contact with humans as well as with ducks, could facilitate reassortment of influenza viruses, which might explain why most pandemics start from that geographical area ${ }^{5}$. Yet, against this background, which suggests that it would be advisable to keep pigs as separate as possible from humans and from water fowl, the adoption of integrated farming and aquaculture systems involving livestock, fowl and fish is being actively encouraged.

The use of fresh manure from farm animals, particularly pigs and ducks, as fertilizer for fish ponds, has a long history in central Europe ${ }^{6}$ and also particularly in Asia $^{7}$. Co-culture of fish and ducks, and of fish and pigs, is widespread in China ${ }^{8.9}$ and in Hong Kong, where both duck-fish and pig-fish culture systems are scattered randomly throughout the main fish culture region ${ }^{7}$. Such polyculture systems are also common in India where, for example, the Central Inland Fisheries Research Institute (CIFRI) issues technical literature for small-scale fish farmers outlining procedures and costings for 'fish-cum-duck' and 'fish-cum-pig' culture. Such farmers in West Bengal are able to produce in fishduck systems up to $4,000 \mathrm{~kg} \mathrm{ha}^{-1} \mathrm{yr}^{-1}$ and in fish-pig systems up to $7,000 \mathrm{~kg} \mathrm{ha}^{-1} \mathrm{yr}^{-1}$ of cultured carp with no supplementary feeding of the fish ${ }^{10}$.

More elaborate artisanal polyculture systems involving fish are also being developed rapidly in various parts of the world. In Thailand, for example, wide use is made of pig-hen-fish culture: the hens are in cages above the pigs which consume hen faeces, and the pigs are in pens directly above fish ponds into which they defecate? ${ }^{7}$. In such systems both excess food from the farm animals and their faecal material are either consumed directly by fish or act as pond fertilizers. Similar systems involving ducks, pigs and fish are used in Hong Kong, Malaysia and Nepal' Indeed, in Hong Kong, a geographical region from which it is known that influenza pandemics have arisen ${ }^{1}$, fish culture activities are very extensive with 48.1 per cent devoted to duck-fish culture, 1.6 per cent to pig-fish culture and 12.2 per cent to duck-pig-fish culture?

The rapid increase in human population in the developing world, where fish often provide a large component of the diet, has coincided with great pressures on wildstock fisheries. Accordingly, the increased world demand for food has coincided with a major expansion in fishfarming, sometimes referred to as the "Blue Revolution'". In the developing world there are obvious advantages in supporting fish-farming projects which are labour intensive and which at the same time provide low-cost fish feeds and pond fertilizers such as are available by combining aquaculture with agriculture. So it is not surprising that countries in the developing world, supported by organizations such as the Food and Agriculture Organization of the United Nations, the International Center for Living Aquatic Resource Management and the UK Overseas Development Administration, are all recommending an increased use of artisanal systems of aquaculture integrated with farm livestock culture. Moreover, extension of such systems is being proposed not only in Asia but elsewhere, by transferring Asian techniques to rural development programmes in Africa ${ }^{8}$. Adoption of these recommendations will result in increased co-location of pigs, humans and ducks, concentrated in artisanal aquaculture industries, in a number of areas throughout the world consistent with religious considerations.

\section{Health hazard}

The result may well be creation of a considerable potential human health hazard by bringing together the two reservoirs of influenza A viruses, generating risks that have not hitherto been considered in assessment of the health constraints of integrated animal-fish farming? In the context of a burgeoning aquaculture industry, they could have global implications for the recurrence of influenza pandemics. Review of integrated aquaculture systems, leading to the development of techniques which keep pigs in enclosed farms separate from waterfowl, is therefore a matter of some urgency.

1. Scholtissek, C., Rohde, W., von Hoyningen, V. \& Rott, R Virology 87, 13-20 (1978).

2. Webster, R.G., Hinshaw, V.S., Bean, W.J. \& Sriram, G. in Influenza (eds Tyrrell, D.A.J. \& Pereira, H.G.) 439-446 (Royal Society, London, 1980).

3. Scholtissek, C., Burger, H., Kistner, O. \& Shortridge, K.F. Virology 147, 287-294 (1985)

4. Hinshaw, V.S., Webster, R.G. \& Bean, W.S. in The Origin of Pandemic Influenza Viruses (ed. Laver, W.G.) 181-189 (Elsevier, New York, 1983).

5. Shortridge, K.F. \& Stuart-Harris, C.H. Lancet ii, 812-813 (1982).

6. Woynarovich, E. in Advances in Aquaculture (eds Pillay, T.V.R. \& Dill, W.A.) FAO Conference on Aquaculture, Kyoto, Japan, 203-208 (FAO, Rome, 1976)

7. Pullin, R.S.V. \& Shehadeh, Z.H. (eds) Integrated Agriculture-Aquaculture Farming Systems ICLARM Conference Proceedings Vol. 4 (ICLARM, Manila, 1980)

8. Freshwater Aquaculture Development in China FAO Fisheries Tech. Pap. No. 215 (FAO/UNDP, Rome, 1983).

. Zhang, F.L., Zhu, Y. \& Zhou, X.Y. Aquaculture 60, 107$116(1987)$

10. Sharma, B.K. Fish-cum-Duck and Fish-cum-Pig Culture (Central Inland Fisheries Research Institute, Barrackpore, India, undated)

11. Roberts, R.J., Stoneman, J. \& Tarbit, J. (eds) Fisheries Research and Development (1976-83) (Overseas Development Administration, London, 1986)

Christoph Scholtissek is at the Institut für Virologie, Justus-Liebig-Universität Giessen, Frankfurter Strasse 107, D-6300 Giessen, FRG. Ernest Naylor is Lloyd Roberts Professor of Zoology, School of Animal Biology, University College of North Wales, Bangor, Gwynedd LL57 $2 U W, U K$. 